Military Technical College Kobry Elkobbah, Cairo, Egypt.

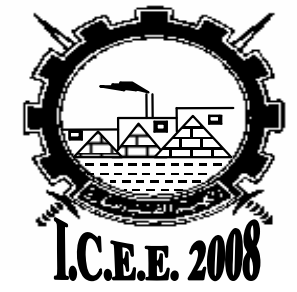

$4^{\text {th }}$ International Conference On Chemical \& Environmental Engineering

27-29 May 2008

\title{
RECOVERY OF PROPIONIC ACID BY REACTIVE EXTRACTION: EFFECT OF TEMPERATURE AND WATER CO-EXTRACTION.
}

\author{
Amit Keshav $^{1}$, Kailas L. Wasewar ${ }^{2 *}$ and Shri Chand ${ }^{3}$
}

\begin{abstract}
Reactive extraction of propionic acid was studied using Aliquat 336 in different diluents (2-octanol and oleyl alcohol). Effects of temperature and water co-extraction on extraction of propionic acid were determined. Study of these parameters is important to design an efficient recovery process for propionic acid recovery. The knowledge of effect of temperature is essential for designing the extraction and backextraction step. Extraction was found to increase with increasing temperature upto 40 ${ }^{\circ} \mathrm{C}$ whereupon it decreases. This suggested that extraction should be performed at temperature around $40{ }^{\circ} \mathrm{C}$, and back extraction at temperature $>60{ }^{\circ} \mathrm{C}$. Water coextraction was found to be highest at low Aliquat concentrations. With increase in acid concentration an increase in co-extracted water was found.
\end{abstract}

\section{KEYWORDS:}

Propionic acid, Reactive extraction, temperature, and water co-extraction

Research scholar, Department of Chemical Engineering, IIT Roorkee, India

Assistant Professor, Department of Chemical Engineering, IIT Roorkee, India

Corresponding Author : Email: k_wasewar@rediffmail.com, klw73fch@iitr.ernet.in Phone: +911332-285347 Fax: +91-1332-276535

3 Professor and Head, Department of Chemical Engineering, IIT Roorkee, India. 


\section{NOMENCLATURE}

$\begin{array}{llll}K_{D} & = & \text { distribution coefficient } & {[-]} \\ K_{E} & = & \text { extraction equilibrium constant } & {\left[\mathrm{m}^{3} / \mathrm{kmol}\right]} \\ {[\mathrm{HA}]} & = & \text { concentration of acid } & {\left[\mathrm{kmol} / \mathrm{m}^{3}\right]} \\ {\left[\mathrm{R}_{4} \mathrm{~N}^{+} \mathrm{Cl}^{-}\right]_{\text {org }}} & = & \text { concentration of Aliquat } 336 & {\left[\mathrm{kmol} / \mathrm{m}^{3}\right]} \\ {\left[\mathrm{R}_{4} \mathrm{~N}^{+} \mathrm{Cl}^{-}: \mathrm{HA}\right]_{\text {org }}} & = & \text { concentration of acid-extractant complex } & {\left[\mathrm{kmol} / \mathrm{m}^{3}\right]} \\ \mathrm{Ka} & = & \text { dissociation constant of acid } & {\left[\mathrm{m}^{3} / \mathrm{kmol}\right]} \\ {[\mathrm{H}]^{+}} & = & \text {concentration of cation } & {\left[\mathrm{kmol} / \mathrm{m}^{3}\right]} \\ \alpha=K_{a} /\left(K_{a}+[\mathrm{H}]^{+}\right) & = & \text {constant, representing part of dissociated form of acid }[-] \\ V & = & \text { volume } & {\left[\mathrm{m}^{3}\right]}\end{array}$

\section{SUBSCRIPTS}

$\begin{array}{lll}\text { aq } & = & \text { aqueous phase } \\ \text { org } & = & \text { organic phase }\end{array}$

\section{SUPERSCRIPTS}

$0=$ initial

\section{INTRODUCTION}

The demand of propionic acid is increasing because of its wide usage in chemical, food and pharmaceutical industries. Calcium, sodium and ammonium salts of propionic acid are broad spectrum preservatives because of their bactericidal, fungicidal, insecticidal and antiviral effects and because of their neutral taste and smell [1]. Industrially, propionic acid is produced by three different processes: carbonylation of ethylene with carbon monoxide and water, oxidation of propanal and direct oxidation of hydrocarbons [2]. High cost and environmentally unfriendly nature of the petrochemical production, leads researchers to focus on the bioproduction route for production of carboxylic acid. Production by fermentation route is a cheap and clean alternative for production but suffer from the high cost and low efficiency of recovery technique for the generated acid. Conventional fermentation technologies for propionic acid production from glucose or lactose are limited by low reactor productivity $(<1 \mathrm{~g} /(\mathrm{I} . \mathrm{h}))$, low product yield $(<50 \% / \mathrm{w})$ and low product concentration $(40 \mathrm{~g} / \mathrm{l})$. The low productivity and low product concentration can be attributed to the fact that propionic acid bacteria are strongly inhibited by propionic acid [3].

The probable solution to the above problem can be an efficient recovery method that can remove acid as soon as it is produced, so that accumulation can be prevented. Currently, method of precipitation is used for recovery, which suffers from problems like waste generation and lot of lime and sulphuric acid consumption [4]. These disadvantages lead to search for alternative methods of recovery. Therefore alternative separation methods have been looked at, that should provide efficient, 
economic and environment friendly recovery. Reactive extraction has been one of the promising technology for recovery of carboxylic acids. Of different extractants available for extraction, aliphatic amines were found to be more effective and less expensive [5]. The complete design of reactive extraction recovery process requires equilibrium, kinetic, thermodynamic, $\mathrm{pH}$ and water co-extraction data.

Tamada et al. [6], studied the effect of temperature and water co-extraction on extraction of succinic acid and lactic acid by Alamine 336 in different diluents. The amount of co-extracted water lie in the same order as the solubility's of water in the diluents with amine present. Enthalpy and entropies of complex formation has been derived from the results of effect of temperature. Baniel et al., [7] found that study of effect of temperature is very useful in design of back extraction process for the recovery of acid. The result of: decrease in extraction with increase in temperature, permit a solution of "temperature swing regeneration", by which if in back extraction step high temperature is maintained, good recovery of acid can be obtained.

In view of the importance of effect of temperature and water co-extraction in recovery of propionic acid from fermentation broth/ waste streams, reactive extraction of propionic acid with Aliquat 336 (tri- $\left(\mathrm{C}_{8} \mathrm{C}_{10}\right)$ methyl ammonium chloride) dissolved in 2octanol and oleyl alcohol was investigated. The data obtained would help in the design of propionic acid extraction system.

\section{EXPERIMENTAL}

All the chemicals (propionic acid, 2-octanol, oleyl alcohol) were of reagent grade and were used without pretreatment. The solutions of propionic acid were prepared using distilled water. Low concentrations $\left(0.05-0.4 \mathrm{kmol} / \mathrm{m}^{3}\right)$ of propionic acid solutions were used, because in practical situations the acid concentration in the fermentation broth is not expected to be greater than $10 \%$.Extractant used was Aliquat 336 (Methyltricaprylammonium chloride), a mixture of $\mathrm{C}_{8}-\mathrm{C}_{10}$ with a minimum assay of 80 $\%$ and with molecular weight of 404.17 and density of $0.888 \mathrm{~g} / \mathrm{cm}^{3}$.

Equal volumes $(25 \mathrm{ml}$ ) of aqueous phase (different concentrations of propionic acid) and organic phases (extractant-diluent) of known concentrations were equilibrated in temperature controlled shaker bath for 24 hours. The two phases were allowed to settle for at least 2 hours, which was sufficient for complete separation [8]. The acid concentration was determined HPLC using C-18 column. The acid content in the organic phase was determined with a mass balance.

\section{RESULTS AND DISCUSSION}

Quaternary ammonium chloride (Aliquat 336) extracts both the dissociated and undissociated forms of acids. Since the experiments were performed at $\mathrm{pH}$ smaller than the pKa of acid (4.67), it was presumed that acid dissociation was negligible. 
Therefore only acid - extractant complex and undissociated acid were presumed to exist in the organic and aqueous solutions respectively. The complexation reaction between Aliquat $336\left(\left[\mathrm{R}_{4} \mathrm{~N}^{+} \mathrm{Cl}\right]_{o r g}\right)$ and propionic acid $\left([\mathrm{HA}]_{a q}\right)$ can be represented as:

$\left[\mathrm{R}_{4} \mathrm{~N}^{+} \mathrm{Cl}\right]_{\text {org }}+[\mathrm{HA}]_{a q} \leftrightarrow\left[\mathrm{R}_{4} \mathrm{~N}^{+} \mathrm{Cl}^{-}: \mathrm{HA}\right]_{\text {org }}$

The equilibrium complexation constant can be defined as:

$K_{E}=\frac{K_{D}}{\left[\mathrm{R}_{4} \mathrm{~N}^{+} \mathrm{Cl}^{-}\right]_{\text {org }}(1-\alpha)}$

where $\alpha=K_{a} /\left(K_{a}+\left[H^{+}\right]\right)$represents the part of dissociated form of acid and $K_{D}=$ $\left.[\mathrm{HA}]_{\text {org }} / \mathrm{HA}\right]_{\mathrm{aq}}$ is the distribution coefficient.

Experiments were carried out to describe the effect of temperature on the extraction of propionic acid using Aliquat in 2-octanol and oleyl alcohol (Figure 1.). The distribution coefficient was found to increase with increase in temperature upto $50{ }^{\circ} \mathrm{C}$ and then decreases. This means that better extraction could be achieved at temperatures between $40-50^{\circ} \mathrm{C}$. This trend is a positive result, as fermentation broth are optimal at temperature of $40^{\circ} \mathrm{C}$, so performing the extraction at this temperature would allow greater extraction than at room temperature. Further since increasing temperature beyond $60{ }^{\circ}$, decrease in extraction was found, it probably suggested the method of temperature swing, for regeneration of acid from loaded organic phase obtained in extraction step. During regeneration, the extract would be contacted with a fresh aqueous stream at a higher temperature to produce an acid laden aqueous product stream and a free organic phase. The concentration of acid achievable though depends upon the amount of change in the extraction equilibrium between temperatures and can be higher than that in the original aqueous feed stream.

The plot of $K_{D}$ versus initial acid concentration was shown in Figure 2. As it can be seen, at 30 and $60{ }^{\circ} \mathrm{C}, \mathrm{K}_{\mathrm{D}}$ values were first increased and then decreased as initial acid concentration was increased. However at $40{ }^{\circ} \mathrm{C}$ there was a continuous increase in $\mathrm{K}_{\mathrm{D}}$ with increase of initial acid concentration in aqueous phase. This assures another advantage of working at $40^{\circ} \mathrm{C}$, where higher distribution coefficients can be obtain at what so ever initial acid concentration of aqueous phases. Table 1 shows equilibrium complexation constant variation with temperature, for propionic acid extraction using Aliquat in 2-octanol and oleyl alcohol at different temperatures. Equilibrium complexation constant was found to be higher at $40{ }^{\circ} \mathrm{C}$ temperatures, thus favoring the extraction to be carried out at the optimum temperature of operation.

Water co-extraction, is the water that enters into the organic phase with the solute. Apparently, forces that allow the diluent to solvate water molecules effectively also cause solvation of the water molecules surrounding or attached to a complex. It 
affects process economics because it may be necessary to recover pure acid from an aqueous solution produced from the extract during regeneration.

Figure 2 shows the plot of $\mathrm{V}_{\text {org }} / \mathrm{V}_{\mathrm{aq}}$ ratio for the extraction of propionic acid using Aliquat in 2-octanol. It can be clearly seen that ratio of organic phase volume to aqueous phase volume was increased with increase in acid concentration. Water coextraction involving $10 \%$ Aliquat was higher that other two cases. The explanation of this phenomenon can be explained on the basis of the diluent and equilibrium characteristics. Since diluent was mainly responsible for the water co-extraction, at high diluent concentration, the water co-extraction was higher; however it was fall as the diluent concentration falls. Further, as water was extracted along with the complexes and at high diluent concentrations, more water was extracted if more acid was present. It was lead to more acid-Aliquat complexes and better solvation provided to them by the diluent, which was in excess. However in general, the selectivity of acid over water in the extraction by amine extractant is high relative to the results with conventional solvent and in all cases the water co-extraction was not above $8-10 \%$, which has little effect on process viability.

\section{CONCLUSION}

The effect of temperature and water co-extraction is important in respect to the process design. With this aim the effect of temperature and co-extraction was studied for extraction of propionic acid using Aliquat 336. The distribution coefficient and equilibrium complexation constants were found to increase with increases in temperature upto certain $50^{\circ} \mathrm{C}$ and thereafter a fall was observed. This provides the process conditions for extraction and regeneration i.e. extraction should be carried out at low temperature $\left(40-50{ }^{\circ} \mathrm{C}\right)$ and back extraction at higher temperatures $(>60$ ${ }^{\circ} \mathrm{C}$ ) in order to achieved an efficient recovery process using Aliquat in respective diluents. Water co-extraction was also studied and was found to be less at higher extractant concentrations. The reason of this being, diluents was responsible for the water co-extraction, the lesser the diluent part, lesser will be amount of water coextracted. However since the total water co-extracted was less that $10 \%$ it should not provide a big effect on the process economics.

\section{ACKNOWLEDGEMENT}

Young Scientist Project, SR/FTP/ETA-43/2005 (DST-276-CHD), Department of Science and Technology (DST), INDIA 


\section{REFERENCES}

[1] Playne, M.J., Moo-Young M., (Eds) Propionic and Butyric acids, Comprehensive Biotechnology, Vol. 3, Pergamon, New York, pp 731(1985).

[2] Ullmann's Encyclopedia of industrial Chemistry. $6^{\text {th }}$ Ed. Vol.26 Wiley-VCH, pp 261-278

[3] Zuwei J. and Yang S.T., Extractive Fermentation for Enhanced Propionic Acid Production from Lactose by Propionibacterium acidipropionici, Biotechnol. Prog., No. 14, pp 457-465 (1998).

[4] Wasewar, K.L., Pangarkar, V.G., Intensification of Propionic Acid Production by Reactive Extraction: Effect of Diluents on Equilibrium, Chem. Biochem. Engg. Q. No.20 (3), pp 1-7, (2006).

[5] King, C.J., Tamada, J.A., Kertes, A.S., Extraction of Carboxylic Acids with Amine Extractants., (1)Equilibria And Law of Mass Action Modeling., American Chem Society, No.29, pp 1319-1326, (1990).

[6] King, C.J., Tamada, J. A., Extraction of Carboxylic acids with amine extractants., (3)Effect of Temperature, Water Co-extraction, and Process Considerations., Ind. Eng. Chem. Res., No. 29, pp 1327-1333 (1990).

[7] Baniel A.M., Blumberg, R., Hadgu K., Recovery of acids from aqueous solutions. British Patent No. 1,426,018, 1973.

[8] Martin, S., Pazos M.C., Coca J., Reactive Extraction of Lactic Acid with Alamine 336 in presence of Salts and Lactose, J. Chemical Tech. and Biotech. No. 54, pp 1-6, (1992). 
Table 1. Effect of temperatures on Equilibrium complexation constant for extraction of propionic acid using Aliquat 336 in different diluents.

\begin{tabular}{|l|l|l|}
\hline Diluent & $\begin{array}{l}\text { Temperature } \\
{ }^{\circ} \mathbf{C}\end{array}$ & $\begin{array}{l}\mathrm{K}_{\mathrm{E}} \\
\mathbf{m}^{\mathbf{3}} / \mathbf{k m o l}\end{array}$ \\
\hline 2-octanol & 30 & 7.66 \\
\hline & 40 & 10.61 \\
\hline & 60 & 10.34 \\
\hline oleyl alcohol & 30 & 3.62 \\
\hline & 40 & 3.95 \\
\hline & 60 & 3.94 \\
\hline
\end{tabular}




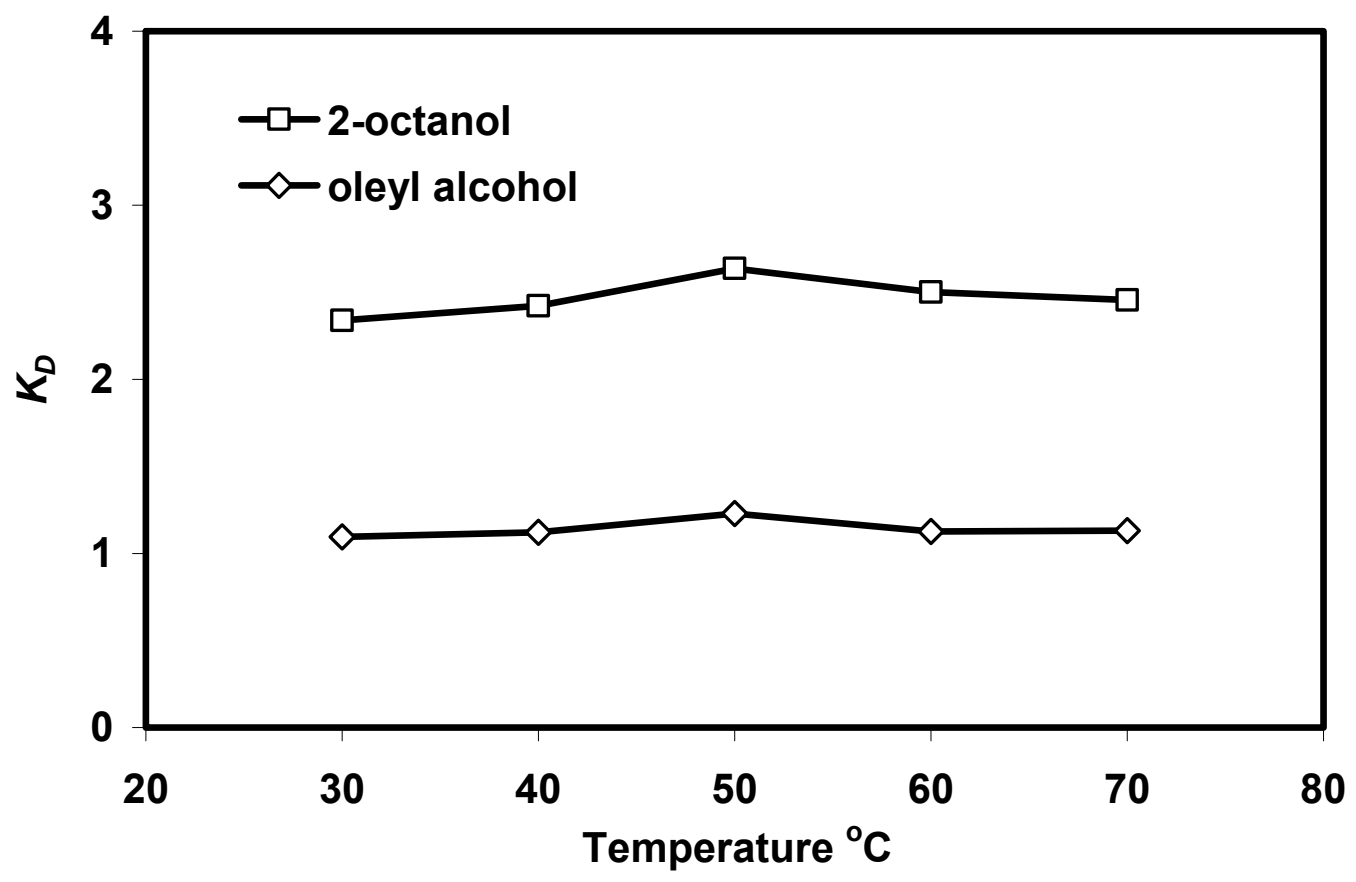

Figure 1: Variation of $K_{D}$ on temperature for extraction of propionic acid using Aliquat 336 in different diluents

$\square$ 2-octanol oleyl alcohol

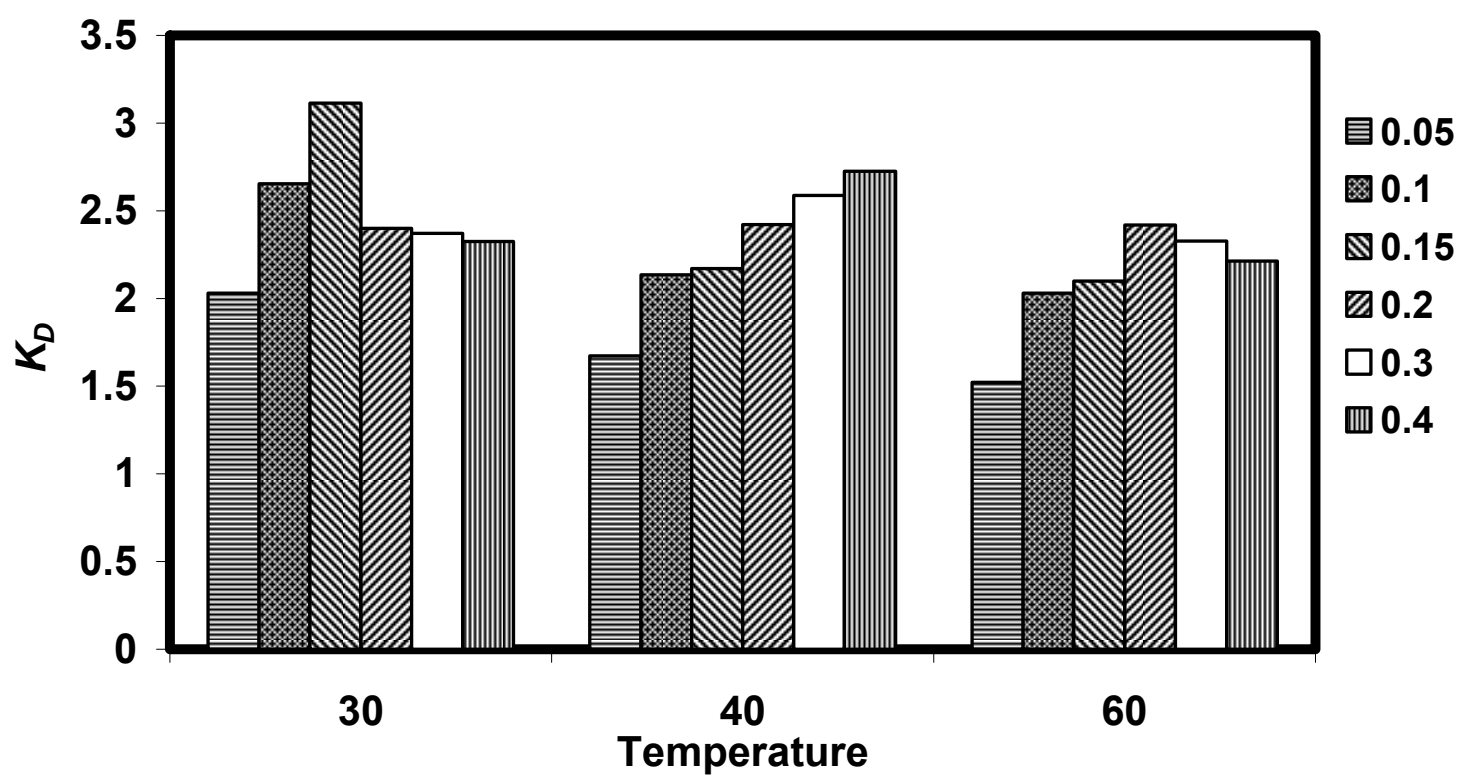

Figure 2: Effect of acid concentration on distribution coefficient for different temperatures for extraction of propionic acid using Aliquat 336 in 2-octanol.

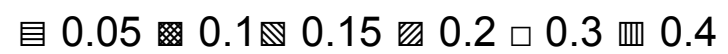




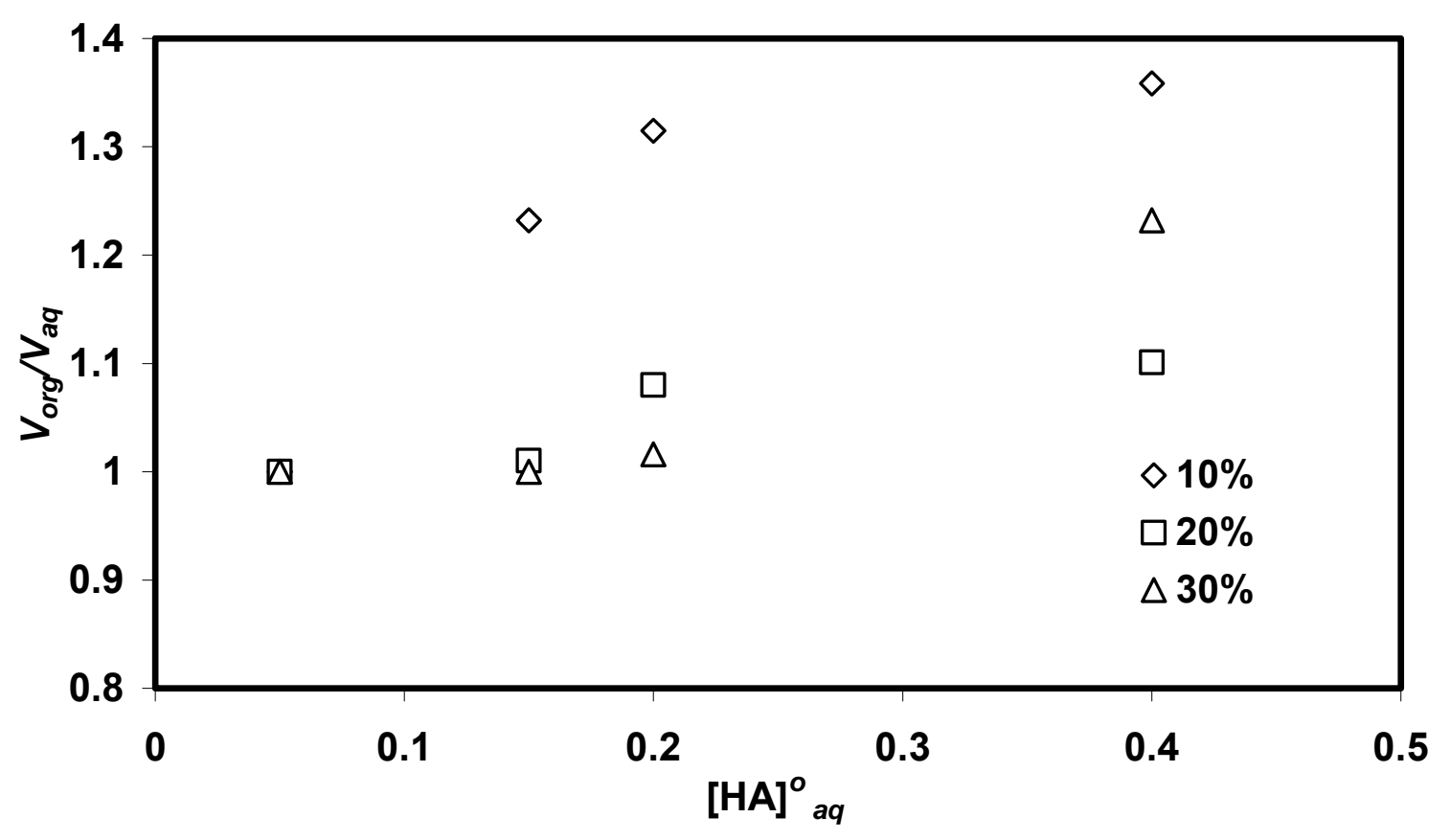

Figure 3. Effect of water co-extraction on extraction of propionic acid using Aliquat $336(10-30 \%)$ in 2-octanol $10 \% \square 20 \% \quad 30 \%$ 